\title{
Factors associated with mortality in newborn infants with meconium aspiration syndrome
}

\author{
Asril Aminullah, Jonardi Sarmili, Sudigdo Sastroasmoro \\ Department of Child Health, Medical School, University of Indonesia, \\ Cipto Mangunkusumo Hospital, Jakarta
}

\begin{abstract}
Meconium aspiration syndrome (MAS) is still one of the common causes of morbidity and mortality in neonatal period. A retrospective study was conducted from January 1993 to December 1999 to identify factors associated with mortality in MAS. Univariate analysis disclosed that preeclampsia/eclampsia, sex. Apgar scores, consistency of meconium, and use of mechanical ventilation were significantly associated with mortality in MAS, while gestational age, mode of delivery, hypertension, birth weight, tracheal suctioning, blood cultures, and complications were not. Logistic regression analysis showed that mode of delivery, preeclampsia/eclampsia, Apgar scores, consistency of meconium, and use of mechanical ventilation were associated with mortality in MAS, while other variables were not. [Paediatr Indones 2001;41:6-10]
\end{abstract}

Keywords: meconium aspiration syndrome, risk factors, infants morbidity and mortality

Meconium ASPIRATION SYNDROME (MAS) IS STILL ONE of the major causes of morbidity and mortality in neonatal period. This syndrome is found in 0.2 .6 per 1000 livc born neonates and it is mostly occurred in babies with meconium-stained amniotic fluid. It is reported that meconium-stained liquor occurs in 10 to $20 \%$ of all deliveries and increases to over $30 \%$ after 42 wceks gestation. From those cases about 2 to $5 \%$ suffered from MAS and with high incidence of morbidity and mortality. About a quarter of those patients were admitted to intensive care units and the mortality rate ranged from 36 to $46 \% .^{1.2}$

The aspiration of mcconium to the respiratory tract can cause physical obstruction of the airways, chemical pneumonitis and surfactant inactivation; all

Correspondence: Asril Aminullah, MD, Department of Child Health, Medical School, University of Indonesia, Jakarta, Jl. Salemba 6. Jakarta 10430, Indonesia. Tel. 62-21-3907742, Fax. 3907743. of these can lead to hypoxemia, hypercapnia, inflammatory changes and dysfunction of alveoli. This conditions sometimes required mechanical ventilation, and mortality is usually associated with complications such as pneumothorax, respiratory failure or persistent hypertension. ${ }^{1.4}$ All kinds of effort have been done to decrease the mortality of patients with this syndrome; however it seems that the mortality rate is still significant. In an attempt to decrease the mortality of MAS, somc investigators have tried to find out factors that are associated with the prognosis of infants with the syndrome. Many perinatal factors arc proved to be associated with the mortality of the disease. Thick meconium and low Apgar scores are among those are reported to have influence on the mortality of newborn infants with MAS. ${ }^{5}$ This study was initiated in our clinic as an effort to identify the perinatal factors that might play a role in the mortality of newborn babies with MAS. 


\section{Methods}

This was a retrospective review of medical records of infants diagnosed to have MAS admitted to Department of Child Health, Medical School, University of Indonesia, Cipto Mangunkusumo Hospital, Jakarta between January 1993 and December 1999. They represented babies who were born in Cipto Mangunkusumo Hospital and patients referred by other clinics in Jakarta. Identification was done to all factors (independent variables) i.e., gestational age, mode of delivery, bir th weight, sex, Apgar scores, consistency of meconium, history of tracheal suction-ing, use of mechanical ventilation, blood cultures, and complications that might associate with mortality of MAS (dependent variable).

The significance of each factor associated with mortality of infants with MAS was first analyzed using univariate analysis. Thereafter a multivariate analysis (logistic regression model) was applicd to find out the contribution of each risk factor after ruling out confounding factors. The level of significance was $\mathrm{p}<0.05$.

TAELE 1. DISTRIBUTION OF FACTORS ASSOCIATED WITH MORTALITY IN MAS

\begin{tabular}{|c|c|c|c|}
\hline Characteristics & & $\mathbf{n}$ & $\%$ \\
\hline \multirow[t]{3}{*}{ Gestational age } & - Preterm & 0 & 0.0 \\
\hline & - Term & 78 & 72.2 \\
\hline & - Postterm & 30 & 27.8 \\
\hline \multirow[t]{3}{*}{ Mode of delivery } & - Spontaneous & 47 & 43.5 \\
\hline & - ForcipalVacuum extraction & 21 & 19.5 \\
\hline & - Cesarean section & 40 & 37.0 \\
\hline \multirow[t]{8}{*}{ Pisk factors } & - No & 34 & 31.5 \\
\hline & - Yes: & 74 & 68.5 \\
\hline & Post term & 30 & 27.8 \\
\hline & Hypertension & 13 & 12.0 \\
\hline & Pulmonary/cardiac disease & 1 & 0.9 \\
\hline & Smoking & 3 & 2.8 \\
\hline & Preeclampsia/eclampsia & 37 & 34.3 \\
\hline & Diabetus mellitus & 2 & 1.9 \\
\hline \multirow[t]{2}{*}{$\operatorname{Sex}$} & - Male & 83 & 76.9 \\
\hline & - Female & 25 & 23.1 \\
\hline \multirow[t]{3}{*}{ Birth weight } & - Low & 13 & 12.0 \\
\hline & - Normal & 89 & 82.4 \\
\hline & - High & 6 & 5.6 \\
\hline \multirow[t]{3}{*}{ Apgar scores } & - Severe asphyxia & 10 & 9.3 \\
\hline & - Mild-moderate asphy ia & 30 & 27.8 \\
\hline & - No as hyxia & 68 & 62.9 \\
\hline \multirow[t]{3}{*}{ Consistency of meconium } & - Mild & 20 & 18.5 \\
\hline & - Moderate & 57 & 52.8 \\
\hline & - Thick & 31 & 28.7 \\
\hline \multirow[t]{2}{*}{ Tracheal suctioning } & - No & 102 & 94.4 \\
\hline & - Yes & 6 & 5.6 \\
\hline \multirow[t]{2}{*}{ Use of ventilation } & - No & 90 & 83.3 \\
\hline & - Yes & 18 & 16.7 \\
\hline \multirow[t]{4}{*}{ Blood culture } & - No & 93 & 86.1 \\
\hline & - Yes: & 15 & 13.9 \\
\hline & Negative & 13 & 12.0 \\
\hline & Positive & 2 & 1.9 \\
\hline \multirow[t]{3}{*}{ Complication } & - No & 105 & 37.2 \\
\hline & - Yes: & 3 & 2.8 \\
\hline & Pneumothorax & 3 & 2.8 \\
\hline \multirow[t]{2}{*}{ Mortality } & - Survived & 71 & 65.7 \\
\hline & - Expired & 37 & 34.3 \\
\hline
\end{tabular}


TABLE 2. ASSOCIATION OF INDEPENDENT VARIABLES AND MORTALITY (UNIVARIATE ANALYSIS)

\begin{tabular}{|c|c|c|c|}
\hline Characteristics & $\begin{array}{c}\text { Survived } \\
(n=71)\end{array}$ & $\begin{array}{c}\text { Explred } \\
(n=37)\end{array}$ & Hypotesis testing \\
\hline \multicolumn{4}{|l|}{ Gestational age } \\
\hline Prelerm & 0 & 0 & $p=0.149$ \\
\hline Term & 47 & 31 & \\
\hline Postterm & 24 & 6 & \\
\hline \multicolumn{4}{|l|}{ Mode of delivery } \\
\hline Spontaneous & 29 & 18 & $p=0.505$ \\
\hline FE - VE & 16 & 5 & \\
\hline Cesarean section & 26 & 14 & \\
\hline \multicolumn{4}{|l|}{ Risk factors } \\
\hline No & 27 & 7 & $O R=2.63(0.93: 7.71) p=0.042$ \\
\hline Yes & 44 & 30 & \\
\hline Post-term & 24 & 6 & $O R=0.37(0.11: 3.21) p=0.064$ \\
\hline Hypeitension & 10 & 3 & $O R=0.54(0.11: 2.36) p=0.365$ \\
\hline Preeclampsia/e clampsia & 15 & 22 & $O R=5.48(2.10: 14.55) p=0.000$ \\
\hline \multicolumn{4}{|r|}{ 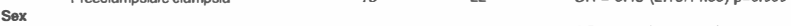 } \\
\hline Male & 59 & 24 & $O R=2.66(0.96: 7.43) p=0.033$ \\
\hline Female & 12 & 13 & \\
\hline \multicolumn{4}{|l|}{ Birth weight } \\
\hline Low & 7 & 6 & $p=0.438$ \\
\hline Normal & 59 & 30 & \\
\hline High & 5 & 1 & \\
\hline \multicolumn{4}{|l|}{ Apgar scores } \\
\hline Severe asphyxia & 1 & 9 & $p<0.0001$ \\
\hline Mild-moderate asphyxia & 17 & 13 & \\
\hline No asphyxia & 53 & 15 & \\
\hline \multicolumn{4}{|l|}{ Consistency of meconium } \\
\hline Mild & 18 & 2 & $\mathrm{p}<0.0001$ \\
\hline Moderate & 42 & 15 & \\
\hline Thick & 11 & 20 & \\
\hline \multicolumn{4}{|l|}{ Tracheal suctioning } \\
\hline No & 67 & 35 & $O R=0.96(0.11: 6.62) p=0.961$ \\
\hline Yes & 4 & 2 & \\
\hline \multicolumn{4}{|l|}{ Use of ventilation } \\
\hline No & 67 & 23 & $O R=10.20(2.71: 41.77) p=0.000$ \\
\hline Yes & 4 & 14 & \\
\hline \multicolumn{4}{|l|}{ Blood cultures } \\
\hline No & 59 & 34 & $p=0.2873$ \\
\hline Yes & 12 & 3 & \\
\hline \multicolumn{4}{|l|}{ Complication } \\
\hline No & 70 & 35 & $O R=4(0.27: 117,70) p=0.230$ \\
\hline Yes & 1 & 2 & \\
\hline
\end{tabular}

\section{Results}

There were 108 cases of MAS identified from January 1993 to December 1999. Most of them were term neonates $(72.2 \%)$, who were delivered spontaneously (43.5\%), had risk factors (68.5\%) i.e., preeclampsia/ eclampsia (34.3\%). Three-quarter of the patients were male (76.9\%). Most of the patients had a normal birth weight $(82.4 \%)$, no asphyxia $(62.9 \%)$, and had a moderate consistency of meconium (52.8\%). Only few cases received tracheal suctioning $(5.6 \%)$ or use of mechanical ventilation (16.7\%). Blood cultures were positive for $E$. coli in 2 patients (1.9\%), and complication such as pneumothorax was found in only 3 patients (2.8\%) (Table 1).

Univariate analysis disclosed that preeclampsia or eclampsia, sex, Apgar scores, consistency of meconium, and use of mechanical ventilation were signifi- 
TABLE 3. RESULTS OF BIVARIATE ANALYSIS AND LOGISTIC REGRESSION AMONG FACTORS ASSO

\begin{tabular}{lcccc}
\hline VARIABLE & \multicolumn{2}{c}{ BIVARIATE } & ANALYSIS & \multicolumn{2}{c}{ LOGISTIC REGRESSION } \\
\cline { 2 - 5 } & Odds ratio & $\mathbf{P}$ & Odds ratio & P \\
\hline Gestational age & & 0,149 & 0,38 & 0,284 \\
Mode of delivery (spontaneous) & & 0,505 & & 0,044 \\
Risk factors & 2,63 & 0,042 & 1,47 & 0,543 \\
Hypertension & 0,54 & 0,365 & 3,89 & 0,094 \\
Preeclampsia/eclampsia & 5,48 & 0,000 & 0,22 & 0,010 \\
Sex (male) & 2,66 & 0,033 & 0,72 & 0,386 \\
Birth weight & & 0,438 & 1,51 & 0,710 \\
Apgar scores & & 0,000 & 0,161 & 0,008 \\
Consistency of meconium & & 0,000 & & 0.002 \\
Tracheal suctioning & 0,96 & 0,961 & $\mathbf{1 , 6 4 6}$ & 0,476 \\
Use of ventilation & 10,20 & 0,000 & 0,294 & 0,005 \\
Blood cultures & & 0,287 & & 0,142 \\
Complication & 4,00 & 0,230 & $\mathbf{1 , 7 4 5}$ & 0,571 \\
\hline
\end{tabular}

cantly associated with mortality in MAS, while gestational age, mode of delivery, hypertension, birth weight, tracheal suctioning, blood culture, and complication were not (Table 2).

Logistic regression analysis with mortality of MAS as dependent variable showed that mode of delivery, preeclampsia/eclampsia, Apgar scores, consistency of meconium, and use of mechanical ventilation were associated with mortality in MAS, while other variables were not (Table 3).

\section{Discussion}

It is reported in many studies that MAS is a disease seen primarily in full-term or post-term infants, and also usually occurs in babies who have experienced some degree of chronic asphyxia which lead to dysmaturity. ${ }^{1.2}$ This condition was also seen in our series of 102 cases of MAS in which there was no single preterm baby was found. On the other hand almost $12 \%$ of the patients were low birth weight babies with some degree of intrauterine growth retardation. It is also seen in our studies, as well as in others; ${ }^{1.2}$ male neonates were more prone to this disorder than female neonates ( $76.9 \%$ vs. $23.1 \%$ ). Whether this is related to the difference of chromosome of male and female infants still needs further investigation.

The syndrome of meconium aspiration usually occurs in babies delivered with meconium stained amniotic fluid. In utero passage of meconium occurs following stimulation of the gut and relaxation of the anal sphincter. It is usually a sign of fetal distress due to intrauterine hypoxia. Therefore all pregnancies associated with fetal distress should be terminated as soon as possible. ${ }^{1.5}$ Several investigators reported that almost all patients with MAS were delivered through cesarean section. ${ }^{6.7}$ In this study, mode of delivery (spontaneous) is related significantly with mortality of MAS. The negative result of mode of delivery in univariate analysis is most probably due to the role of confounding factor.

In preeclampsia/eclampsia there arc incomplete invasion of trophoblast into spiral arteries and incomplete denervation of adrenergic nerves in uteroplacental bed. Both resulting in vasoconstriction of the spiral arteries and cause minimal interchange of nutrient-gases and finally affect the fetus condition. ${ }^{8}$ Mothers with complicated pregnancy such as preec. lampsia/eclampsia often come or are referred late to hospital, therefore no optimal labor monitoring could be done. As noted by Adhikari et $\mathrm{al}_{r}{ }^{2}$ labor monitoring is the most significant factor in reducing the occurence of MAS, leading to better survival and less prolonged resuscitation and mechanical ventilation required. In this study, both univariate and multivariate analysis showed strong correlation between preeclampsia/eclampsia and mortality of MAS.

Apgar scores were included among factors that associated with MAS mortality because review of literature showed that severe asphyxia combined with 
MAS had the gravest prognosis. ${ }^{5}$ Asphyxia inhibits pulmonary capillary flow and rcabsorption of fetal lung fluid, resulted to lung unresponsiveness to the insult produced by meconium. ${ }^{9}$ According to literature the consistency of meconium play a great role in the prognosis of MAS. Thin meconium flow easily to terminal bronchioles from which it can be absorbed without causing any problem; complication is therefore not produced and absorption of meconium is complete. ${ }^{5}$ Our study showed that both Apgar scores and consistency of meconium werc significantly associated with mortality of MAS.

Mechanical ventilation is used for MAS infants who havc respiratory acidosis or severc respiratory distress. Vidyasagar ${ }^{5}$ reported that mortality among infants who required mechanical ventilation was around $30 \%$. This is the reason for authors to include the use of mechanical ventilation as a factor associated with mortality. Statistical analysis significantly confirmed the relation of mechanical ventilation and mortality. However, tracheal suctioning and complication, which reported to be associated with mortality, were not proved in this study, most probably because of limited patients who received tracheal suctioning or those who developed complications.

To sum up, we have proven that mortality of newborn babies with MAS is associated with several perinatal factors, i.e. mode of delivery, preeclampsia/eclampsia, Apgar scores, consistency of meconium, and use of mechanical ventilation. This result should be considered in preventing the development of MAS.

\section{References}

1. Wiswell TE, Bent RC. Meconium staining and the meconium

North Am 1993;40:955-81.

2. Adhikari M, Gouws E, Velaphi SC, Gwamanda P. Meconium aspiration syndrome: importance of the monitoring of labor.J Perinatol 1998; 18:55-60.

3. Carson BS. Suctioning the meconium-swined infant. Am JDis Child 1988;142: 698-9.

4. Eichenwald EC. Meconium aspiration. Dalam: Creasy RK, Resnik R, editors. Manual of neonatal care; 4th edition. Philadelphia: Lippincott; 1998. p. 388-91.

5. Vidyasagar D, Andreou A. Management of meconium aspiration syndrome. In: Aladjem S, Brown AK, editors. Perinatal intensive care. St. Louis: Mosby; 1977. p. 413-25.

6. Meis PJ, Hall M, Marshall JR, et al. Meconium passage: a new classification for risk assessment labor. Am J Obstet Gynecol 1978;131:509-13.

7. Rossi EM, Philipson EH, Williams TG, Kalhan SC. Meconium aspiration syndrome: intrapartum and neonaatributes. Am J Obstet Gynecol 1989;161:1 106-10.

8. Zuspan FP. Hypertensive disorders of pregnancy. In: Fanaroff AA, Martin RJ, editors. Neonavel perinatal medicine. Disease of the fetus and infant; 6 th edition. St. Louis: Mosby; 1997.p. 241-57.

9. Katz VL, Bowes WA. Meconium aspiration syndrome: reflection on a mur ky subject. Am J Obstet Gynecol 1992; 166:171-83. 